\title{
Reduced Arousals Following Obstructive Apneas in Infants Sleeping Prone
}

\author{
JOSÉ GROSWASSER, TONY SIMON, SONIA SCAILLET, PATRICIA FRANCO, AND \\ ANDRE KAHN \\ Sleep and Development Unit, University Children's Hospital Queen Fabiola, Free University of Brussels, \\ 1020 Brussels, Belgium [J.G., T.S., S.S., A.K.]; Pediatric Sleep Unit, Hôpital Erasme, Free University of \\ Brussels, 1070 Brussels, Belgium [P.F.]
}

\begin{abstract}
A decreased arousability and an increased risk for sudden infant death syndrome (SIDS) have been shown in infants sleeping prone. Obstructive apnea, a known risk factor for SIDS, is less often terminated by an arousal reaction in infants than in adults. The effect of body position on the arousal reaction to spontaneous respiratory events had not been previously studied in infants. The aim of our study was to see if body position has an influence on the frequency and delay of the arousal reaction to obstructive apnea. All obstructive events recorded during two successive nights in 20 infants sleeping one night prone and one night supine were studied. During the supine recording 153 obstructive events were detected, and 217 were detected during the prone session. Prone sleep was not associated with an increased frequency of obstructive apneas. Total sleep time was 382 min (range, 283-456) supine and 423 min (range, 325-521) prone $(p=0.003)$. Obstructive events duration was $6.5 \mathrm{~s}$ (range, 3-21.5) when sleeping supine and $8 \mathrm{~s}$ (range, 3.5-30.5) when
\end{abstract}

ABSTRACT

prone $(p=0.002)$. Behavioral arousal were found in $57.5 \%$ of obstructive events recorded supine and in $31.3 \%$ of those seen prone $(p<0.001)$. Arousal occurred after $8 \mathrm{~s}$ (range, $0-21)$ from the start of the obstructions when supine and $10.5 \mathrm{~s}$ (range, $3.5-23.5)$ when prone $(p=0.001)$. Sighs were found in $34 \%$ of supine obstructive events and in $44.7 \%$ of those prone $(p=$ 0.040 ). A reaction, i.e. arousal or sigh, was found in $91.5 \%$ of supine events and $76 \%$ of those prone $(p<0.001)$. We conclude that when sleeping supine, infants arouse to obstructive events more often and after shorter delay than when prone. (Pediatr Res 49: 402-406, 2001)

Abbreviations
SIDS, sudden infant death syndrome
NREM, nonrapid eye movements
REM, rapid eye movements
RR, interval between two R waves

An impaired arousability from sleep was postulated to contribute to the occurrence of SIDS (1). Prospective sleep studies showed that infants who eventually died of SIDS had less body movements and aroused less frequently from sleep than control subjects (2-4). Infants considered at risk for SIDS had higher arousal thresholds for respiratory, tactile, and visual stimuli than control infants $(1,5-8)$. Normal infants studied in risk conditions for SIDS, such as sleeping prone, aroused less frequently (9), had higher arousal thresholds (10), and less cardiac variability (11) than when sleeping supine.

Future SIDS victims were also shown to have more frequent and longer obstructive sleep apneas than control subjects (2). In adults, obstructive apneas are often terminated by an arousal (12). Such apnea-induced arousals were reported to occur less frequently in infants $(13,14)$, although most studies did not

Received March 12, 2000; accepted October 30, 2000.

Correspondence and reprint requests: José Groswasser, MD, Sleep and Development Unit, Hôpital universitaire des enfants Reine Fabiola, 15 Av. J.J. CROCQ, 1020 Bruxelles, Belgique.

Supported by grant no. 1.5.192.94F of the FNRS. take in account the potential contributing effect of body position.

The aim of the present study was to determine whether infants sleep position influences the cardiac and arousal responses following obstructive sleep apneas.

\section{METHODS}

Patients. Twenty-two successive infants with repeated obstructive sleep apnea were investigated (Table 1). The apneas had been identified during polygraphic sleep recordings, done during various sleep research studies on infants' cardiorespiratory characteristics. Infants with an index of $\geq 0.3$ obstructive events per hour sleep were considered as having repeated obstructive apneas and entered the present study if no cause was found for the apneas following a medical examination (2). The infants had no neurologic or respiratory impairment other than obstructive apneas. All infants were considered healthy and were receiving no medication. Care was taken to avoid any sleep deprivation the night before the study was conducted. 
Table 1. Characteristics of the infants studied

$\begin{array}{lc}\text { No. of infants } & 20 \\ \text { Male/female } & 12 / 8 \\ \text { Premature/term infants } & 5 / 15 \\ \text { Gestational age (wk) } & 39(31-42) \\ \text { Postnatal age (wk) } & 7.5(3-13) \\ \text { Postconceptional age (wk) } & 46(40-53) \\ \text { Prone-supine/supine-prone recordings } & 9 / 11\end{array}$

Figures represent absolute, median, and range values.

The study was approved by the local ethics committee, and informed consent by the parents was obtained for each infant.

Polygraphic studies. Each infant was recorded during two successive nights. The infants were randomly assigned to the prone or the supine sleep position during the first night, and the second night was spent in the opposite position. Infants remained in the same position during the whole night.

Polygraphic studies were conducted in a quiet and darkened room at an ambient temperature of $20^{\circ} \mathrm{C}$. The infants slept without restraint and were continuously observed. Their behavior and all nursing interventions were charted. Feeding was given based on demand. Care was taken to avoid neck flexion or displacement of the electrodes. No infant used a pacifier during the study.

The data were collected on computerized polygraphs (Alice III, Healthdyne, Marietta, GA, USA). The following variables were simultaneously recorded: scalp EEG, electro-oculogram, ECG, thoracic respiratory movements, and airflow by thermistors taped under the nostrils and over the upper lip. Gross body movements were detected by an actigram placed on one hand. Oxygen saturation was recorded continuously from a transcutaneous sensor (Nelcorr, Hayward, CA, USA).

Data analysis. All recordings were analyzed visually without knowledge of recording conditions and body position. Thirty-second periods were scored and categorized as either NREM sleep, REM sleep, indeterminate sleep, or awakening according to criteria recommended in the literature $(15,16)$. Indeterminate sleep was scored together with REM sleep as active sleep.

Sleep apneas were scored if they lasted $3 \mathrm{~s}$ or more. Three types of apneas were detected. A central apnea was scored when flat tracings were obtained simultaneously from the thoracic leads and the thermistors. An obstructive apnea was scored when continuous deflections were obtained from the thorax, whereas a flat tracing was obtained from the thermistors. Mixed apneas were defined as a central apnea directly followed by an obstructive apnea. Obstructive and mixed apneas were scored together as obstructive breathing events. To avoid scoring of obstructive events attributable to thermistors displacement, any doubtful episode such as obstructed breathing preceded by a movement or a sigh was rejected. The possibility thus exists that some obstructive apneas were unduly excluded from the study. A sigh was defined as a single breath of at least twice the amplitude of the preceding breaths.

Heart rate was calculated on 6-s moving periods. For the analysis, the period directly preceding the obstructed event and the lowest heart rate accompanying the obstructed events were taken in account. An increased RR interval was defined as an increase of at least $50 \%$ of the RR duration when compared with the mean of the $10 \mathrm{RR}$ intervals preceding the obstructed event.

A behavioral arousal was scored if signs of electroencephalographic desynchronization, eye opening, and body movements were seen simultaneously on the polygraphic recording $(10,17,18)$.

Statistical analysis was done using the SPSS 8.0 for Windows software. Differences between the two nights recordings were evaluated with the Wilcoxon rank test and the MannWhitney test for the continuous variables and Fisher exact test for nominal variables. Spearman rank correlation was used to compare night 1 and 2. The significance level was $p<0.05$.

Results. Of the 22 infants, two infants were excluded from the study because of poor technical quality of the recordings. All infants were usual side or supine sleepers. The main characteristics of the 20 infants who entered the study are presented in Table 1.

Table 2 and Figure 1 represent the main individual cardiorespiratory and arousal characteristics during the supine and prone sessions.

Table 3 represents the main sleep, cardiorespiratory, and arousal characteristics during the prone and supine sessions.

When sleeping prone, infants had an increased $(p=0.003)$ total sleep time (median, $423 \mathrm{~min}$; range, 325-521) than when sleeping supine (median, $382 \mathrm{~min}$; range, 283-456). There was no difference in REM sleep, when sleeping prone (median of $60.3 \%$; range, $40.4 \%-81 \%$ ) or supine (median of $59.2 \%$; range: $42.9 \%-74.8 \%$ ) .

Body position did not modify the frequency of central apneas, with 5.6 central apnea per hour sleep (range, 0.6-53.2) when the infants slept supine and 4.8 (range, 0.9-37.5) when the infants slept supine.

During the study, 370 obstructed events were scored: 153 in the supine position, 217 in the prone position. Body position was not significantly related to the number of obstructed events. During supine sleep a median of 5.5 events were recorded (range values, $0-21$ ), and 4.5 events during prone sleep (range values, 1-51) (NS). The median frequency of obstructed events was 0.6 per hour of sleep when sleeping supine (range values, $0.1-6.3$ ) and 0.9 events when prone (range values, 0-3.1) (NS). From supine to prone, 9 patients had a decreased frequency of obstructive events, whereas 10 increased their frequency.

Of all obstructed events, $93.5 \%$ occurred in REM sleep with the infants laid supine, and $79.7 \%$ when prone $(p<0.001)$.

The proportion of mixed apneas increased significantly during the prone sleep sessions. When sleeping prone, $58.1 \%$ of the obstructed breathing events were obstructive apneas, for $74.5 \%$ when sleeping supine ( $p=0.002)$.

The mixed apneas had comparable durations of central (median, $5 \mathrm{~s}$; range values, 3-20 s) and obstructive portions (median, $6 \mathrm{~s}$; range values, 3-23.5 s). The obstructive apneas were significantly longer in the prone (median, 6.5 ;; range values, $3.5-18.5 \mathrm{~s}$ ) than in the supine position (median, $6 \mathrm{~s}$; range values, $3-17 \mathrm{~s})(p=0.03)$.

When all obstructed breathing events were computed together, the duration of the events increased from $6.5 \mathrm{~s}$ (range, 
Table 2. Individual values of main cardiorespiratory characteristics

\begin{tabular}{|c|c|c|c|c|c|c|c|c|c|c|c|c|}
\hline \multirow[b]{2}{*}{ Patient } & \multirow[b]{2}{*}{ GA } & \multirow[b]{2}{*}{ LA } & \multicolumn{5}{|c|}{ Supine } & \multicolumn{5}{|c|}{ Prone } \\
\hline & & & $\mathrm{CA} / \mathrm{Hr}$ & $\mathrm{OE} / \mathrm{Hr}$ & $\mathrm{N} \mathrm{OE}$ & $\mathrm{N} A R$ & $\% \mathrm{AR}$ & $\mathrm{CA} / \mathrm{Hr}$ & $\mathrm{OE} / \mathrm{Hr}$ & $\mathrm{N} \mathrm{OE}$ & $\mathrm{N}$ AR & $\% \mathrm{AR}$ \\
\hline DEK J (M) & 34 & 6 & 10.3 & 2.3 & 16 & 11 & 69 & 10.0 & 1.4 & 8 & 2 & 25 \\
\hline ARR N & 40 & 6 & 6.5 & 0.9 & 6 & 4 & 67 & 11.1 & 0.5 & 4 & 0 & 0 \\
\hline TEX D & 42 & 5 & 1.1 & 0.6 & 4 & 3 & 75 & 0.6 & 0.1 & 1 & 1 & 100 \\
\hline VDB A & 36 & 8 & 2.5 & 0 & 0 & - & - & 1 & 0.4 & 3 & 2 & 67 \\
\hline GIL M & 40 & 13 & 6.1 & 0.4 & 3 & 2 & 67 & 7.4 & 0.4 & 3 & 2 & 67 \\
\hline MAR F & 42 & 9 & 4.5 & 0.7 & 4 & 3 & 75 & 5.0 & 0.1 & 1 & 0 & 0 \\
\hline GEN L & 37 & 7 & 5.1 & 0.8 & 5 & 4 & 80 & 4.2 & 0.2 & 1 & 0 & 0 \\
\hline VAI M & 34 & 10 & 5.1 & 2.0 & 15 & 6 & 40 & 5.3 & 2.5 & 19 & 3 & 16 \\
\hline JEA M & 37 & 3 & 8.9 & 0.8 & 4 & 3 & 75 & 3.5 & 6.3 & 34 & 6 & 18 \\
\hline BAS S & 40 & 6 & 0.9 & 1.5 & 11 & 8 & 73 & 1.4 & 1.2 & 10 & 5 & 50 \\
\hline MAL A & 40 & 11 & 4.3 & 0.1 & 1 & 1 & 100 & 7.2 & 0.3 & 2 & 1 & 50 \\
\hline ALG E & 41 & 5 & 2.0 & 1.6 & 8 & 5 & 63 & 5.7 & 0.3 & 2 & 1 & 50 \\
\hline DUR B & 40 & 10 & 1.5 & 0.6 & 4 & 3 & 75 & $\begin{array}{r}5.7 \\
\end{array}$ & 0.9 & 6 & 2 & 33 \\
\hline KUB F & 31 & 9 & 1.9 & 3.1 & 21 & 14 & 67 & 4.8 & 3.5 & 28 & 12 & 43 \\
\hline
\end{tabular}

$\mathrm{CA} / \mathrm{Hr}$, central apneas per hour sleep; OE/Hr, obstructive events per hour sleep; N OE, number obstructive events; N AR, number arousals; \% AR, proportion of obstructive events with arousal reaction during the supine and prone sessions; GA, gestational age at birth; LA, legal age at time of sleep recording.

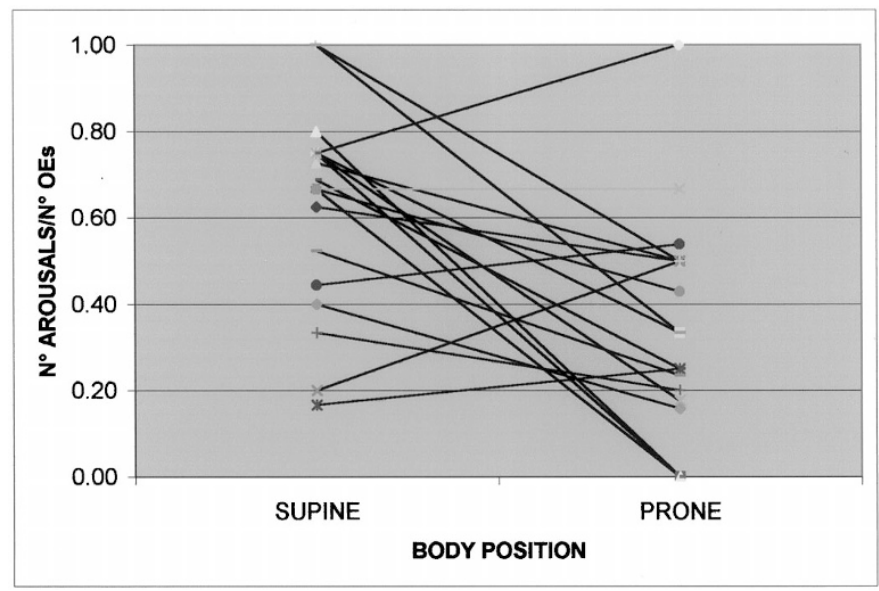

Figure 1. Proportion of apnea-induced arousals per infant. The figure represents the frequency of arousals according to body position. When prone, fewer arousals were seen in 15 infants; more frequent arousals were seen in 4 infants; no difference was seen in 1 .

$3-21.5 \mathrm{~s}$ ) when sleeping supine to $8.0 \mathrm{~s}$ (range, 3.5 to $30.5 \mathrm{~s}$ ) when prone $(p=0.002)$.

Before the obstructed events, basal heart rates were higher during the prone (median of $142 \mathrm{bpm}$; range, 124-163 bpm) than during the supine position (median, $135 \mathrm{bpm}$; range, $106-158 \mathrm{bpm})(p<0.001)$. After the obstructive events, the heart rates were higher in the prone (median, $110 \mathrm{bpm}$; range, 71-136 bpm) than in the supine position (median, $97 \mathrm{bpm}$; range, $72-126 \mathrm{bpm})(p<0.001)$. Following the obstructive breathing events, there were no difference in the frequency of heart rate drops $(38.2 \%$ of drops when prone, $39.2 \%$ when supine), or in the level of the drops (median of $20.8 \%$ of basal heart rate; range, $7.4-46.6 \mathrm{bpm}$ ) prone or supine (median of $21.9 \%$ of basal heart rate; range, $4.8-49.3 \mathrm{bpm}$ ).

The number of obstructed events accompanied by increases in RR intervals was lower in the prone position (41.9\%) than in
Table 3. Sleep, cardiorespiratory, and arousal characteristics during supine and prone sleep

\begin{tabular}{|c|c|c|c|}
\hline & Supine & Prone & $p$ \\
\hline Total sleep time (min) & $382(283-456)$ & $423(325-521)$ & $0.003 *$ \\
\hline Obstructive events (OE) & $n=153$ & $n=217$ & \\
\hline $\begin{array}{l}\text { Duration (s) obstructive } \\
\text { apneas }\end{array}$ & $6(3-17)$ & $6.5(3.5-18.5)$ & $0.030 \dagger$ \\
\hline All OE & $6.5(3-21.5)$ & $8(3.5-30.5)$ & $0.002 \dagger$ \\
\hline \multicolumn{4}{|l|}{ Behavioral arousals } \\
\hline No. of arousals & 88 & 68 & - \\
\hline OE with arousals (\%) & 57.5 & 31.3 & $<0.001 \%$ \\
\hline Delay from start of OE (s) & $8.0(0-21.0)$ & $10.5(3.5-23.5)$ & $0.001 \dagger$ \\
\hline Duration of the arousals (s) & $7(3-30)$ & $12(3-29)$ & $0.002 \dagger$ \\
\hline \multicolumn{4}{|l|}{ Sighs } \\
\hline No. of all sighs & 52 & 97 & - \\
\hline OE with sighs $(\%)$ & 34.0 & 44.7 & $0.040 \%$ \\
\hline No. of isolated sighs & 40 & 86 & - \\
\hline OE with isolated sighs (\%) & 26.1 & 39.6 & $0.010 \%$ \\
\hline \multicolumn{4}{|l|}{ Arousals and sighs } \\
\hline Total number & 140 & 165 & - \\
\hline OE with arousal or sigh & 91.5 & 76.0 & $<0.001 \ddagger$ \\
\hline
\end{tabular}

$$
(\%)
$$

The figures represent absolute, frequencies, medians, and ranges values.

* Wilcoxon rank test.

$\dagger$ Mann-Whitney test.

$\$$ Fisher exact test.

supine position $(56.2 \%)(p<0.01)$. The longest RR interval was smaller when sleeping prone (median, $0.675 \mathrm{~s}$; range, $0.500-1.125 \mathrm{~s}$ ) than when sleeping supine (median, $0.775 \mathrm{~s}$; range, $0.500-1.250 \mathrm{~s})(p=0.001)$.

The obstructed breathing events were followed by a behavioral arousal in $31.3 \%$ of the events during prone sleep, and in $57.5 \%$ of supine sleep $(p<0.001)$. The delay between the start of the obstructed breathing event and the arousal was significantly longer in the prone (median, $10.5 \mathrm{~s}$; range, 3.5-23.5 s) than in the supine position (median, $8 \mathrm{~s}$; range, $0-21 \mathrm{~s})(p=$ $0.001)$. The behavioral arousal reaction followed the end of the 
obstructed events with the same delay in both body positions (median, $0 \mathrm{~s}$; range, $8 \mathrm{~s}$ before and $14.5 \mathrm{~s}$ after). The duration of the arousal reaction was longer in the prone (median, $12 \mathrm{~s}$; range, 3-9 s) than in the supine position (median, $7 \mathrm{~s}$; range, 3-30 s.) $(p=0.002)$. The behavioral arousal led to complete awakenings in $3.8 \%$ of events, or were followed by sleep resumption with sleep stage modification $(30.1 \%)$. Fifteen infants aroused more frequently to apnea when sleeping supine, 4 aroused less frequently, and no difference was noted for one infant (Fig. 1).

Obstructed breathing events were more often followed by a sigh in the prone (in $44.7 \%$ of events) than in the supine position $(34 \%)(p<0.05)$. The difference was particularly significant for isolated sighs, which are sighs not followed by a central apnea $(39.6 \%$ of events during prone, and $26.1 \%$ during supine sleep; $p=0.01$ ).

The number of obstructive events during sessions 1 and 2 were highly correlated (Spearman rank correlation coefficient $0.626 ; p=0.003$ ) as were the number of central apneas (Spearman rank correlation coefficient $0.753 ; p<0.001$ ), although no correlation was found in the proportion of arousal reaction to obstructive events in night 1 and night 2 (Spearman rank correlation $-0.272: p=0.26$ ).

No differences were seen when the above findings were analyzed in NREM or REM separately. None of the above differences could be attributed to gestational age, gender, or order of body position.

\section{DISCUSSION}

The present study shows that an obstructive sleep apnea is less often accompanied by an arousal, and that the arousal reaction occurs later when the infant sleeps prone rather than when supine. This observation sustains reports of less frequent apnea-induced arousals in infants and children $(13,14)$ than in adults (12). In addition, our study shows a significant difference in the frequency of apnea-induced arousals associated with sleep position, as a behavior arousal is seen following $31.3 \%$ of apneas during prone sleep, and $57.5 \%$ in supine sleep.

We have no explanation as to why arousals occur less frequently in the prone than in the supine position. The present findings are reminiscent of previous observations showing that compared with the supine, the prone body position is characterized by a reduced number of spontaneous arousals (9), an increase in auditory arousal threshold (10), and a decrease in arousal reaction to tilting in active sleep (19). The delayed occurrence of the arousal reaction during prone sleep could contribute to the increased duration of the obstructed event in these children.

When sleeping prone, the infants had a higher basal heart rhythm before and after the obstructed breathings and had less frequent increases in RR intervals than when sleeping supine. The findings could be related to the increased orthosympathetic cardiac control level associated with the prone body position (11). It is also reminiscent of previous studies showing that prone sleep was associated with increased heart rate, decreased peripheral vasomotor tone, and increased peripheral skin temperature $(20,21)$. In one of these studies $(21)$, the authors indicate that sleep is associated with an alteration in baroreceptor function, which could be further enhanced if the infant sleeps prone. It could be hypothesized that this reduction in baroreceptor function may induce a depressed reaction to the increased negative pressure observed in the thorax during obstructed breathing (22).

The present observations cannot be attributed to experimental conditions, as factors known to modify arousability from sleep were controlled, such as previous sleep deprivation (23, 24 ), order of body position assignment (9), or environmental conditions. The present experimental factors were shown not to contribute to the frequency of obstructive apneas in infants, such as potential "first night effect" (25) or the influence of body position (9). In addition, no difference could be seen between nights 1 and 2 for all factors studied, and there was a high correlation between nights 1 and 2 for obstructive events and central apneas. The absence of correlation between nights 1 and 2 for the arousal reaction can be attributed to the random order of body position during the two recorded nights. As all infants were usual supine sleepers, we cannot exclude however that different apnea-related reactions could have been found in usual prone sleepers.

When sleeping prone, the infants had a higher frequency of sighs following the obstructed breathing events than when sleeping supine. The sighs could represent incomplete or partial arousal reactions, as has been observed previously $(26,27)$. When combining the number of sighs and behavioral arousals, $91.5 \%$ of supine and $76 \%$ of prone infants would have either a partial or a complete arousal.

It remains to be confirmed whether our findings relate to mechanisms responsible for SIDS. Compared with control infants, future SIDS victims were shown to have more frequent obstructive apneas $(2,28)$, and to arouse less frequently from sleep (2). Factors known to increase the risks for SIDS, such as prone sleeping $(9-11,29)$, prenatal exposure to cigarette smoke (30), high environmental temperature (31), or the use of sedative medications (32) were also associated with lower arousability. Arousal from sleep represents an autoresuscitative mechanism (26). A decreased propensity to arouse following obstructive sleep apneas could increase the risk to become victim of a life-threatening event, such as obstructive sleep apneas.

In conclusion, when laid prone to sleep, infants have fewer and delayed arousal reactions to obstructive events, than when laid supine. These results could contribute to understand why prone position is associated with an increased risk for SIDS.

Acknowledgments. The authors thank the nursing staff and Ms F. Modard for their constant help.

\section{REFERENCES}

1. Newman NM, Trinder JA, Phillips KA, Jordan K, Cruicshank J 1989 Arousal deficit: mechanism of the sudden infant death syndrome? Aust Paediatr J 25:196-201

2. Kahn A, Groswasser J, Rebuffat E, Sottiaux M, Blum D, Foerster M, Franco P, Bochner A, Alexander M, Bachy A, Richard P, Verghote M, Le Polain D, Wayenberg L 1992 Sleep and cardiorespiratory characteristics of infants victims of sudden death: a prospective case-control study. Sleep 15:287-292

3. Coons S, Guilleminault C 1985 Motility and arousal in near miss sudden infant death syndrome. J Pediatr 107:728-732 
4. Schechtman VL, Harper RM, Wilson AJ, Southall DP 1992 Sleep state organization in normal infants and victims of the sudden infant death syndrome. Pediatrics $89: 865-870$

5. Hunt CE 1981 Abnormal hypercarbic and hypoxic sleep arousal responses in nearmiss sudden infant death syndrome infants. Pediatr Res 15:1462-1464

6. Brady JP, McCann EM 1985 Control of ventilation in subsequent siblings of victims of sudden infant death syndrome. J Pediatr 106:212-217

7. McCulloch K, Brouillette RT, Guzetta AJ, Hunt CE 1982 Arousal response in near-miss sudden infant death syndrome and in normal infants. J Pediatr 101:911-917

8. Davidson-Ward SL, Bautista DB, Sargent CW, Keens TG 1990 Arousal responses to sensory stimuli in infants at increased risk for sudden infant death syndrome. Am Rev Respir Dis 104:A809

9. Kahn A, Groswasser J, Sottiaux M, Rebuffat E, Franco P, Dramaix M 1993 Prone or supine body position and sleep characteristics in infants. Pediatrics 91:1112-1115

10. Franco P, Pardou A, Hassid S, Lurquin P, Groswasser J, Kahn A 1998 Auditory arousal thresholds are higher when infants sleep in the prone position. J Pediatr 132:240-243

11. Franco P, Groswasser J, Sottiaux M, Broadfield E, Kahn A 1996 Decreased cardiac responses to auditory stimulation during prone sleep. Pediatrics 97:174-178

12. Collard P, Dury M, Delguste P, Aubert G, Rodenstein DO 1996 Movement arousals and sleep-related disordered breathing in adults. Am J Respir Crit Care Med 154:454-459

13. Thoppil CK, Belan MA, Cowen CP, Mathew OP 1991 Behavioral arousal in newborn infants and its association with termination of apnea. J Appl Physiol 70:2479-2484

14. MacNamara F, Issa FG, Sullivan CE 1996 Arousal pattern following central and obstructive breathing abnormalities in infants and children. J Appl Physiol 81:25512557

15. Rechtschaffen A, Kales A (ed) 1968 A Manual of Standardized Terminology, Techniques and Scoring System for Sleep Stages of Human Subjects. U.S. Government Printing Office, Washington, DC

16. Anders T, Emde R, Parmelee AH (eds) 1971 A Manual of Standardized Terminology, Techniques and Criteria for Scoring of States of Sleep and Wakefulness in Newborn Infants. UCLA Brain Information Service, NINDS Neurological Information Network, Los Angeles

17. Carskadon MA 1994 Monitoring and staging human sleep. In: Kryger MH, Roth T, Dement WC (eds). Principles and Practice of Sleep Medicine. WB Saunders, Philadelphia, pp 934-960
18. ASDA Report (The Atlas Task Force) 1992 EEG arousals: scoring rules and examples. Sleep 15:173-184

19. Galland BC, Reeves G, Taylor BJ, Bolton DPG 1998 Sleep position, autonomic function and arousal. Arch Dis Child Fetal Neonatal Ed 78F:189-194

20. Skadberg BT, Markestad T 1997 Behavior and physiological responses during prone and supine sleep in early infancy. Arch Dis Child 76:320-324

21. Chong A, Murphy N, Matthews T 2000 Effect of prone sleeping on circulatory control in infants. Arch Dis Child 82:253-256

22. Guilleminault C, Stooh R 1992 From apnea of infancy to obstructive sleep apnea syndrome in the young child. Chest 102:1065-1071

23. O’Donnell CP, King ED, Schwartz AR, Smith PL, Robotham JL 1994 Effect of sleep deprivation on responses to airway obstruction in the sleeping dog. J Appl Physiol 77:1811-1818

24. Canet E, Gaultier C, D'Allest AM, Dehan M 1989 Effects of sleep deprivation on respiratory events during sleep in healthy infants. J Appl Physiol 66:1158-1163

25. Rebuffat E, Groswasser J, Kelmanson I, Sottiaux M, Kahn A 1994 Polygraphic evaluation of night-to-night variability in sleep characteristics and apneas in infants. Sleep 17:329-332

26. Thach BT, Lijowska A 1996 Arousals in infants. Sleep 19(suppl 10):S271-S273

27. Scaillet S, Groswasser J, Franco P, Simon T, Essangha C, Kahn A 1998 Sighs as part of the arousal reaction to auditory stimuli. Proceedings of the $14^{\text {th }}$ European Congress on Sleep Research, Madrid, Spain

28. Guilleminault C, Stoohs R, Skrobal A, Labanowski M, Simmons J 1993 Upper airway resistance in infants at risk for sudden infant death syndrome. J Pediatr 122:881-886

29. American Academy of Pediatrics 1992 AAP Task Force on Infant Sleeping Position and SIDS. Positioning and SIDS. Pediatrics 89:1120-1126

30. Franco P, Groswasser J, Hassid S, Lanquart JP, Scaillet S, Kahn A 1999 Prenatal exposure to cigarette smoking is associated with a decrease in arousal in infants. J Pediatr 135:34-38

31. Franco P, Szliwowski H, Groswasser J, Dramaix M, Kahn A 1997 The influence of temperature on sleep characteristics and autonomic nervous system in healthy infants. (abstract). Proceedings of the $7^{\text {th }}$ ESPID (European Society for the Prevention of Infant Death) Congress, Barcelona, Spain, p 44

32. Kahn A, Hasaerts D, Blum D 1985 Phenothiazine-induced sleep apneas in normal infants. Pediatrics 75:844-847 